\title{
Emergency intrauterine device insertion in teenagers: an informal retrospective study
}

\author{
Hannat Akintomide, ${ }^{1}$ Suganthi Vinayagam, ${ }^{2}$ Catherine Schünmann ${ }^{3}$
}

\begin{abstract}
${ }^{1}$ Specialty Doctor, NHS Camden Provider Services - Sexual \& Reproductive Health, Margaret Pyke Centre, London, UK

${ }^{2}$ Clinical Fellow, Reproductive Medicine, Old St Mary's Hospital, Central Manchester University Hospitals NHS Foundation Trust, Manchester, UK

${ }^{3}$ Consultant in Sexual and Reproductive Health, Contraception \& Sexual Health (CASH) Clinic, Norwich, UK
\end{abstract}

\section{Correspondence to} Dr Catherine Schünmann, Consultant in Sexual and Reproductive Health, Contraception \& Sexual Health (CASH) Clinic, Grove Road, Norwich NR1 3RH, UK; catherine.schunmann@nnuh.nhs.uk

Received 24 October 2013 Accepted 7 January 2014 Published Online First 3 March 2014

\section{CrossMark}

To cite: Akintomide $\mathrm{H}$, Vinayagam S, Schünmann C. $J$ Fam Plann Reprod Health Care 2014;40:196-199.

\begin{abstract}
Background Widespread and increased

availability of oral emergency contraception (EC) over the past 10 years has made little difference to rates of unintended pregnancy, abortion and repeat abortion amongst teenagers. The insertion of an intrauterine device for EC (ECIUD) is $98-99 \%$ effective compared with $85 \%$ for oral methods and can be used for ongoing, long-term reversible contraception. However this method is seldom used for teenagers, a group with a high risk of unintended pregnancy, and there is little published data on the use of ECIUD in this group.
\end{abstract}

Methods An anonymous case note review of EC-IUD use in teenagers in three centres in the UK was conducted to quantify provision, to identify insertion difficulties and short-term complications and to ascertain compliance with national guidance concerning sexually transmitted infection (STI) risk assessment and prophylaxis.

Results A total of 103 cases was identified over 4 years (2007-2010) from the three centres (London, Liverpool and Aberdeen). The results show that the majority of fittings were straightforward (94\%) with few complications. Antibiotic prophylaxis was deemed necessary in $64 \%$ of attenders.

Conclusions The authors recommend that with STI screening and appropriate antibiotic prophylaxis, use of IUDs in women under the age of 20 years should be unrestricted both for long-term contraception and for EC.

\section{INTRODUCTION}

Widespread and increased availability of oral emergency contraception (EC) over the past 10 years has made disappointingly little difference to rates of unintended pregnancy, abortion and repeat abortion amongst teenagers. Conceptions in this age group remain a major area of public health concern. ${ }^{1}{ }^{2}$ Use of an

\section{Key message points}

- The majority of fittings of intrauterine devices (IUDs) for emergency contraception (EC) in teenagers are straightforward with few immediate complications.

- Current Health and Social Information Centre data show that EC-IUD is provided for $2 \%$ of all teenagers requesting EC from community contraceptive clinics compared with $8 \%$ of older women.

- With sexually transmitted infection screening and appropriate antibiotic prophylaxis, the use of IUDs for EC in teenagers should be unrestricted as it is for women aged $\geq 20$ years.

intrauterine device (IUD) for EC (EC-IUD) is $98-99 \%$ effective and offers the option to continue the method for long-term reversible contraception, yet this is seldom offered to teenagers. ${ }^{3}$

Young age, nulliparity and sexually transmitted infection (STI) risk are not contraindications to the use of EC-IUD ${ }^{4}$ and published guidance suggests that this method should be discussed with all women requesting EC. Providers of oral EC should be able to refer or signpost women to services where prompt EC-IUD insertion is available.

Data on EC-IUD use by teenagers are scarce although there is some evidence of increasing use of IUDs for postcoital contraception in this group over the past 5 years. $^{3}$

A retrospective case note review of EC-IUD use in teenagers was conducted in three centres in the UK, with three main objectives: to quantify provision, to 
identify any problems with insertion and short-term retention, and to determine practice concerning STI screening.

\section{METHODS}

The authors aimed to identify 100 EC-IUD insertions in women aged 13-19 years. The three specialist Sexual and Reproductive Health (SRH) services in which the authors were working (London, Liverpool and Aberdeen, UK), were selected based on their estimated caseload and the availability of relevant data. Cases were identified using the Sexual Health and Activity Dataset KT31, service electronic patient records and manual database review, together with paper case note review. As overall numbers of teenagers provided with EC-IUD were low, records were identified in each centre as far back as the existence of retrievable data allowed (London and Liverpool 2008-2010, Aberdeen 2007-2010).

Demographic and clinical details were recorded on a purpose-designed data collection form, entered onto a spreadsheet and analysed with Microsoft Excel ${ }^{\mathrm{TM}}$. Recommendations of the Faculty of Sexual Health \& Reproductive Healthcare (FSRH) Clinical Guidance documents on Intrauterine Contraception $2007^{5}$ and Emergency Contraception 2011 (originally 2007, updated 2012) ${ }^{4}$ regarding STI risk assessment, antibiotic prophylaxis and immediate provision of oral EC were used as nationally accepted, measurable standards of good medical practice when providing EC. These documents recommend pre-insertion screening for STIs in high-risk groups (including age $<25$ years), consideration of antibiotic prophylaxis to cover at least Chlamydia trachomatis if test results are unavailable at IUD insertion and the provision of oral EC if an IUD cannot be inserted immediately.

All three services complied with local protocols for approval of data gathering for audit purposes. Research Ethics Committee approval was not required as the data were collected by anonymous case note review.

\section{RESULTS}

Each of the participating centres is an SRH clinic providing specialised contraceptive care. The Aberdeen and Liverpool clinics are regional centres and the London clinic serves the central area of the city. Each centre provides EC-IUD following self-referral or referral by another agency. For comparative purposes, total EC requests in each centre in 2010 were 801, 5438 and 985 for the London, Liverpool and Aberdeen centres, respectively, of which 89/801 (11\%), 1927/5438 (35\%) and 377/985 (38\%) were from teenagers.

In total, case notes or patient records for 103 EC-IUD insertions in teenage women were identified with 13 performed in London, 64 performed in Liverpool and 26 performed in Aberdeen. Details of the women together with the time of EC-IUD insertion after intercourse are shown in Table 1. Most of these young women were in the 18-19 years age group and only 10 were aged under 16 years. The majority were nulliparous (87\%) and most (71\%) required EC following unprotected sexual intercourse rather than for failure of a barrier or hormonal method.

Details of the insertion procedure, its timing, use of local anaesthesia (LA) and cervical dilatation, and outcomes are shown in Table 2. Only six insertions were described as being difficult and one was not completed. When the EC-IUD could not be inserted immediately, oral EC was provided in all but one case. All women underwent a risk assessment for STI. Swabs were taken in $66(64 \%)$ of cases and antibiotic prophylaxis (azithromycin $1 \mathrm{~g}$ orally) was given to 46 $(45 \%)$ women.

Table 1 Characteristics of the study population

\begin{tabular}{|c|c|}
\hline Characteristic & $\begin{array}{l}n(\%)^{*} \\
(n=103)\end{array}$ \\
\hline \multicolumn{2}{|l|}{ Age at EC-IUD insertion (years) } \\
\hline 13 & $1(1)$ \\
\hline 14 & $2(2)$ \\
\hline 15 & $7(7)$ \\
\hline 16 & $7(7)$ \\
\hline 17 & $14(14)$ \\
\hline 18 & $21(21)$ \\
\hline 19 & $51(50)$ \\
\hline \multicolumn{2}{|l|}{ Parity } \\
\hline 0 & $90(87)$ \\
\hline$\geq 1$ & $6(6)$ \\
\hline Unknown & $7(7)$ \\
\hline \multicolumn{2}{|c|}{ Previous termination of pregnancy or miscarriage } \\
\hline 0 & $89(86)$ \\
\hline 1 & $13(13)$ \\
\hline 2 & 1 (1) \\
\hline \multicolumn{2}{|l|}{ Reason for EC } \\
\hline Unprotected sexual intercourse & $73(71)$ \\
\hline Condom failure & $27(26)$ \\
\hline Hormonal method failure & $3(3)$ \\
\hline \multicolumn{2}{|c|}{ Time to EC-IUD insertion (hours after intercourse) } \\
\hline$<24$ & $10(10)$ \\
\hline $24-48$ & $20(19)$ \\
\hline $48-72$ & $21(20)$ \\
\hline $72-96$ & $18(18)$ \\
\hline $96-120$ & $27(26)$ \\
\hline$>120 \dagger$ & $7(7)$ \\
\hline \multicolumn{2}{|c|}{ Child safeguarding issue identified (in 10 under-16s) } \\
\hline Yes & $4(40)$ \\
\hline No & $6(60)$ \\
\hline \multicolumn{2}{|c|}{$\begin{array}{l}\text { *Percentages have been rounded up to the nearest whole number. } \\
\dagger>120 \text { hours from intercourse but }<5 \text { days from earliest expected } \\
\text { ovulation date. } \\
\text { EC, emergency contraception; IUD, intrauterine device. }\end{array}$} \\
\hline
\end{tabular}


Table 2 Insertion procedures, timings, use of local anaesthesia and cervical dilatation, and outcomes

\begin{tabular}{|c|c|}
\hline EC-IUD insertion procedure & $\begin{array}{l}n(\%) \\
(n=103)\end{array}$ \\
\hline \multicolumn{2}{|l|}{ Oral EC given as well as EC-IUD } \\
\hline Yes & $64(62)$ \\
\hline No & $38(37)$ \\
\hline Data missing & $1(1)$ \\
\hline \multicolumn{2}{|l|}{ Timing of EC-IUD insertion } \\
\hline Immediate & $78(76)$ \\
\hline Interval & $25(24)$ \\
\hline \multicolumn{2}{|c|}{ Interval insertion and oral EC $(n=26)$} \\
\hline With oral EC & $25(96)$ \\
\hline Without oral EC & 1 (4) \\
\hline \multicolumn{2}{|l|}{ Ease of EC-IUD insertion } \\
\hline Easy & $37(36)^{*}$ \\
\hline Average & $59(57)$ \\
\hline Difficult & $6(6)$ \\
\hline Failed & $1(1)$ \\
\hline \multicolumn{2}{|l|}{ Use of local anaesthesia } \\
\hline Yes & $24(23)$ \\
\hline No & $79(77)$ \\
\hline \multicolumn{2}{|l|}{ Cervical dilatation required } \\
\hline Yes & $13(13)$ \\
\hline No & $90(87)$ \\
\hline \multicolumn{2}{|l|}{ Retention of EC-IUD } \\
\hline Removed $\dagger$ & $28(27)$ \\
\hline Retained $\neq$ & $18(18)$ \\
\hline Unknown & $56(55)$ \\
\hline Failed initial fit & $1(1)$ \\
\hline
\end{tabular}

*One 'easy' insertion was complicated by device removal 1 hour later due to pain.

tOne device was removed an hour after insertion as above, the remaining 27 were removed $\geq 6$ weeks after insertion.

¥Retention was recorded if women visited the clinic subsequently and were using the IUD for contraception (time interval 11-35 months).

EC, emergency contraception; IUD, intrauterine device.

Follow up was noted for any women attending the clinic at any time following the EC-IUD insertion either for a routine check or any other reason. Excluding one removal that took place 1 hour after insertion, 27 (26\%) women requested removal of the device at some time after their next menstrual period. Their reasons were: pain and bleeding (21, $75 \%$ of removal requests), partial expulsion (2, both 3 months post-insertion), planned temporary insertion (2), wishing another method (1) and planning pregnancy (1). One teenager presented 18 months after EC-IUD insertion with a pregnancy associated with IUD failure. She had undergone an abdominal ultrasound for suspected gallstones 16 months after the EC-IUD insertion and was informed that the IUD was "low lying". No further action was taken until she had a positive pregnancy test 2 months later. There were no clinic records of any other unintended pregnancies in any of the women, but this does not exclude the possibility of pregnancies that were not reported to the clinics.

\section{DISCUSSION}

This case note review of 103 EC-IUD insertions in teenagers has shown that the majority of procedures are straightforward, with few immediate complications. Data from the Lifestyle Statistics section of the Health and Social Care Information Centre (HSCIC) ${ }^{3}$ show that this highly effective and long-acting method of EC is used less frequently in teenagers compared with women aged over 20 years. In 2011-2012, HSCIC data show that $2 \%$ of teenagers requesting EC from a community contraceptive clinic were provided with EC-IUD compared with $8 \%$ of women over the age of 20 years. There are no other published studies concerning EC-IUD use in this age group.

Most EC-IUD use was amongst older teenagers, and despite a high proportion (87\%) being nulliparous, difficult and failed insertions were the exception as was the need to use cervical dilators. Most devices $(87 \%)$ were fitted without the use of LA although data were not available to allow determination of whether LA was routinely offered in accordance with FSRH guideline advice, so this may reflect either patient choice or individual practitioner preference.

STI risk assessments were carried out on all teenagers resulting in two-thirds of the group having swabs taken and antibiotic prophylaxis being given to just under half. These findings suggest that practitioners are aware of the need to screen for STIs but seem less likely to give prophylactic antibiotics, perhaps because some teenagers have already been screened or because they are in an established relationship of over 12 months or because they decline antibiotics. The authors feel that there should be a low threshold for prophylaxis in this group as chlamydia is the most common bacterial STI in the UK and rates of infection are substantially higher in teenagers. ${ }^{1}$

Although $27 \%$ of the women were known to have had their IUD removed at some point after 6 weeks, the primary aim of insertion, the avoidance of an unintended pregnancy at the time of requesting EC, had already been achieved. Eighteen women were confirmed as having their IUD in situ at a later visit to the clinic and the outcome for the remainder (55\%) is unknown as they did not return within the duration of the study. Of note is the absence of return by any teenager for an immediate complication. It is impossible to exclude their attendance at other services for this reason but it seems unlikely that significant short-term complications remained undetected. Although this was not a prospective study and full records are therefore not available, it is most unlikely that there were any unintended pregnancies as a result of failure of EC-IUD.

A systematic review of IUD use in adolescents (generally teenagers but with two studies with age ranges up to 20 and 22 years) by Deans and Grimes ${ }^{6}$ summarised 13 studies between 1973 and 2007 and concluded that existing data were "sparse and obsolete". None of the studies concerned EC-IUD and 
participant numbers were small. Expulsion rates varied between $5 \%$ and $22 \%$.

Four subsequent studies have been published, with a total of 328 insertions of IUDs for contraception, but not for EC, in teenagers. ${ }^{7-10}$ These looked primarily at postinsertion outcomes rather than the ease or difficulty of the procedure. Expulsion rates varied from 5\% to $15 \%$, there were no perforations and there were two cases of removal within 48 hours of insertion due to pain.

Only three other small studies of IUD use in teenagers $\left(25,48\right.$ and 14 participants, respectively) ${ }^{11-13}$ could be identified and these concerned placement under general anaesthesia (except in one case) either at the time of bariatric surgery or primarily for menstrual control (levonorgestrel intrauterine system). They reported similarly low rates of expulsion but did not comment on ease of insertion.

Published evidence suggests that there is interest in EC-IUD amongst young women ${ }^{14}$ and that this interest can be increased by the use of educational interventions designed to inform teenagers about the method. ${ }^{15}$ Specialist providers of contraception and health promotion initiatives should encourage women of all ages to use the most effective methods of contraception, which include EC-IUD for teenagers.

\section{CONCLUSIONS}

Insertion of an IUD is rarely provided for EC for teenagers although FSRH guidance supports its use regardless of age or parity. The data collected in this study show that fitting devices in teenagers is seldom difficult and, in common with published data, results in very few adverse outcomes. The authors' anecdotal experience suggests that an increasing number of services and practitioners offer LA routinely, which would make insertion even easier. These data should provide some reassurance for those who feel reluctant to offer EC-IUD to teenagers. The incidences of expulsion $(2 / 103,2 \%)$ and early removal for pain $(1 / 103,1 \%)$ in the present study compare favourably with the existing data.

Taken together with a $1 \%$ rate of failed insertion, the evidence suggests that the use of intrauterine methods in teenagers, the majority of whom were nulliparous, does not result in significant problems. The authors recommend that with STI screening and appropriate antibiotic prophylaxis, the use of IUDs for EC and for ongoing contraception in teenagers should be reclassified from UKMEC 2 (a condition where the advantages of using the method generally outweigh the theoretical or proven risks) to UKMEC 1 (a condition for which there is no restriction for the use of the contraceptive method), as it is for women aged over 20 years.

Acknowledgements The authors would like to extend their thanks to the staff at The Margaret Pyke Centre, London, Abacus Sexual Health Service, Liverpool and Grampian Sexual Health Service, Aberdeen (previously known as Square 13) for their assistance in data collection. The authors are also grateful to Professor Siladitya Bhattacharya, University of Aberdeen and
Professor Anna Glasier, London School of Hygiene \& Tropical Medicine and the University of Edinburgh, for their overview, comments and suggestions.

Competing interests None.

Provenance and peer review Not commissioned; externally peer reviewed.

\section{REFERENCES}

1 Public Health Outcomes Framework for England 2013-2016. http://www.uk.gov.uk/publications/healthylives [accessed 20 October 2013].

2 Sexual Health \& Blood Borne Virus Framework 2011-2015. http://www.scotland.gov.uk/Publications/2011/08/2408570 [accessed 20 October 2013].

3 Health \& Social Care Information Centre. NHS Contraceptive Services - England, 2011-2012, Community contraceptive clinics. Table 7. http://www.hscic.gov.uk [accessed 20 October 2013].

4 Faculty of Sexual \& Reproductive Health Care Clinical Effectiveness Unit. Clinical Guidance. Emergency Contraception. 2011 (updated January 2012). http://www.fsrh. org/pdfs/CEUguidanceEmergencyContraception11.pdf [accessed 20 October 2013].

5 Faculty of Sexual \& Reproductive Health Care Clinical Effectiveness Unit. Clinical Guidance. Intrauterine Contraception. 2007. http://www.fsrh.org/pdfs/ CEUGuidanceIntrauterineContraceptionNov07.pdf [accessed 20 October 2013].

6 Deans EI, Grimes DA. Intrauterine devices for adolescents: a systematic review. Contraception 2009;79:418-423.

7 Paterson H, Ashton J, Harrison-Woolrych M. A nationwide cohort study of the use of the levonorgestrel intrauterine device in New Zealand adolescents. Contraception 2009;79:433-438.

8 Lara-Torre E, Spotswood L, Correia N, et al. Intrauterine contraception in adolescents and young women: a descriptive study of use, side effects and compliance. J Pediatr Adolesc Gynecol 2011;24:39-41.

9 Godfrey EM, Memmel LM, Neustadt A, et al. Intrauterine contraception for adolescents aged 14-18 years: a multicentre randomised pilot study of levonorgestrel-releasing intrauterine system compared to the copper T380A. Contraception 2010;81:123-127.

10 Patchem L, Berggren EK. Use of the copper T380 intrauterine device by adolescent mothers: continuation and method failure. J Pediatr Adolesc Gynecol 2011;24:71-73.

11 Hillman JB, Miller RJ, Inge TH. Menstrual concerns and intrauterine contraception among adolescent bariatric surgery patients. J Womens Health 2011;20:533-538.

12 Aslam N, Blunt S, Latthe P. Effectiveness and tolerability of levonorgestrel intrauterine system in adolescents. J Obstet Gynaecol 2012;30:489-491.

13 Pillai M, O'Brien K, Hill E. The levonorgestrel intrauterine system (Mirena) for the treatment of menstrual problems in adolescents with medical disorders, or physical or learning disabilities. BJOG 2010;117:216-221.

14 Bimla Schwarz E, Kavanaugh M, Douglas E, et al. Interest in intrauterine contraception among seekers of emergency contraception and pregnancy testing. Obstet Gynecol 2009;113:833-839.

15 Whitaker AK, Terplan M, Gold MA, et al. Effect of a brief educational intervention on the attitudes of young women toward an intrauterine device. J Pediatr Adolesc Gynecol 2010;23:116-120. 